\title{
Comparative Study of Electronics Visualisation Techniques for E-Learning
}

\author{
http://dx.doi.org/10.3991/ijep.v2i2.2085 \\ A. Touhafi ${ }^{1,3}$, A. Braeken ${ }^{1}$, L. Sterckx ${ }^{1}$, Y. Verbelen ${ }^{1}$, F. Gueuning ${ }^{2}$, C. Flémal ${ }^{2}$, \\ F. Defrance ${ }^{2}$ and Ph. Dekimpe ${ }^{2}$ \\ ${ }^{1}$ Erasmushogeschool Brussel, Brussels, Belgium \\ ${ }^{2}$ Haute Ecole Léonard de Vinci (ECAM), Brussels \\ ${ }^{3}$ Vrije Universiteit Brussel, Brussels, Belgium
}

\begin{abstract}
We developed a learning platform that integrates three different existing methods for virtual experiments in the context of electronics and electricity. These methods include the Falstad simulator, a web service based SPICE simulator in electronics, and an attractive $3 \mathrm{D}$ visualization model with preliminary web interface called Videofmodels. Based on this platform, we evaluated the representation and perception of each method. The main conclusion that could be drawn from our study was that the simple self-explaining interactive technique, obtained by the Falstad simulator, will be, at this time, the best model in a self-study environment. On the other hand, the attractive three dimensional representation of the Videomodels, seems to play an important role in motivating the students during the lessons but an improved graphical visualization model and web interface seems to be required.
\end{abstract}

Index Terms-e-learning platform, virtual experiments, SPICE simulator, Videomodels, Fallstad simulator

\section{INTRODUCTION}

The main problem when teaching electricity and electronics is the presence of abstract and invisible entities such as current and voltage. These parameters only become visible through measurements with the oscilloscope. An extra difficulty is the high dimensionality and dynamics in electronic circuits. Therefore, studying efficiently electronics requires sufficient lab experience in order to obtain a better insight in these electrical principles. Students with insufficient access to the lab, because of several reasons (sickness, combination of studies with full time job,...), will be seriously disadvantaged. A way to overcome this lack of practice is the use of interactive multimedia in a virtual learning environment. It is already shown in lots of studies that the use of several forms of multimedia for learning electronics has been very useful and appreciated by students.

In our study, three existing animation/simulation techniques are placed in an e-learning context and evaluated by students. The first technique is called Videomodels and represent videos that show dynamically a three dimensional view of the electronic circuit. It is the only system that enables to give a view in one glance on all the relevant parameters in the circuit. The second method is based on the two dimensional graphs of the SPICE simulator, the standard simulator for analog and mixed-mode circuit simulation. The data of the SPICE simulations are exchanged through a web service. The web service is im- plemented by means of Microsofts Windows Communication Foundation, guaranteeing the interoperability of the simulator thanks to XML based SOAP messages. Finally, the last simulation technique consists of an existing JAVA applet, very well known in educative context, made by Paul Falstad. This applet enables the complete design of the circuit and uses color coding for representing currents and voltages.

The e-learning environment which has been developed for our test setup is implemented in ASP.NET. It offers the three types of simulation tools in an integrated multilingual web-environment. The developed webenvironment is conceptually build as a modular and expandable web-site where XML and XLST are used for content description and lay-out formatting. The educative content is accompanied with corresponding questions.

The website and the three multimedia based virtual experiment systems are evaluated by 37 Bachelor students industrial engineering of the Erasmushogeschool Brussel with respect to representation, documentation, interface, understanding and their own perception on efficiency. From the evaluation, we received an idea of the most important characteristics in an e-learning system.

The paper is organized as follows. Section II gives an overview of related work. In Section III, we shortly explain the three different systems and how they were placed in a web context. Section IV describes the format of the learning platform that integrates these three systems. In Section $\mathrm{V}$, the evaluation of the different techniques is described. This evaluation is analysed in Section VI. We end with conclusions and future work in Section VII.

\section{RELATED WORK}

Interactive multimedia through simulations and animations have been proven to be a great support in better understanding of the basic concepts in electronics and electrics. In the past, several systems have been realized that successfully offered simulations and animations [1], [2], [3], [4], [5], [6]. In all these initiatives, we could draw the following remarks.

- The e-learning tools are mostly used for teaching concepts in power electronics.

- The electrical variables are often represented twodimensional, based on a color coding to represent voltages or current values.

- Interactivity is often implemented with technologies such as JAVA or FLASH. 
PAPER

- The multimedia is produced ad-hoc for e-learning.

- The report of the used multimedia is poorly documented with evaluation of students.

The goal of this paper is to compare three existing and completely different systems in order to get a better understanding of the importance of the functionalities and restrictions in each of the systems. This work is also part of the feasibility study of a web interface for Videomodels.

The first system, Videomodels, is different from all other systems, due to its three dimensional character. For the second system, we chose the SPICE simulator, which is the de facto standard (off-line) simulator of electronic circuits. As last system, we took the Falstad simulator, a JAVA applet that can also be used on mobile platforms. At the time of implementation, the first two systems, Videomodels and SPICE, were only available as off-line multimedia, and thus had to be first brought to a web context.

\section{MULTIMEDIA SYSTEMS}

We now shortly describe the three different systems that we combined in the learning platform: SPICE simulator, Videomodels and Falstad simulator. We conclude this section with an overview of the main technical characteristics for each of the three systems.

\section{A. SPICE simulator}

SPICE is the abbreviation of Simulation Program with Integrated Circuit Emphasis. The program enables to predict the behavior of electronic circuits. The original version was developed in the late sixties by Nagel and Peterson [7]. Currently, it is seen as the standard for analog and mixed-mode circuit simulation. Due to the release of the SPICE code as open source, many commercial software packages with extensive user interface are based on it.

In order to bring the SPICE simulator in an e-learning context, a web based application with a Graphical User Interface (GUI) should be provided for the simulator. Communication should be realized between the computer of the student (client) and the server that hosts the web application. Approximately 10 years ago, in [8] and [9], some implementations have been proposed. However, both approaches are closed implementations which do not offer an application interface for third party web developers. Moreover, the interaction with the end user is rather slow. Instead of a client-server implementation strategy, we have chosen to create a Service Oriented Architecture (SOA). We created a web service which offers SPICE simulations as a Service. An important advantage is that web developers become platform independent and should no longer care about coding the transfer of netlists and SPICE data. We refer to [10] for more technical details of the implementation. Fig. 1 (top) shows an example of the SPICE simulator in the learning platform.

\section{B. Videomodels}

F. Gueuning developed the concept of Videomodels at the Haute Ecole Léonard de Vinci (ECAM) in Brussels in 2001. A Videomodel represents computed simulation data that is generated by a SPICE simulator as a three dimensional animation of a circuit. Currents in a circuit branch are represented by cones which grow proportional with the current value. At the same time voltages are represented using a waterfall-representation. The higher the voltage on a circuit node, the higher the node is drawn in the three dimensional circuit representation. The result is an animated circuit in which currents and voltages are the forces which create a mechanical moving circuitrepresentation. This way currents and voltages in the circuit become less abstract and get a physical and easy to understand equivalent.

At ECAM, the Videomodels have been proven to be very successful and are extensively used during the courses. The teacher is able to rapidly show many details, usually too complex to be seen by other methods, such as the transients at power-on of a transistor amplifier [11]. Fig. 1 (middle) shows an example of the Videomodel in the learning platform.

The electronic components in Videomodels are rendered for each voltage value. This is necessary due to the fact that the terminals of the component have changing voltages during operation. Figure 2 shows how an NPN transistor is rendered for different voltage values on the

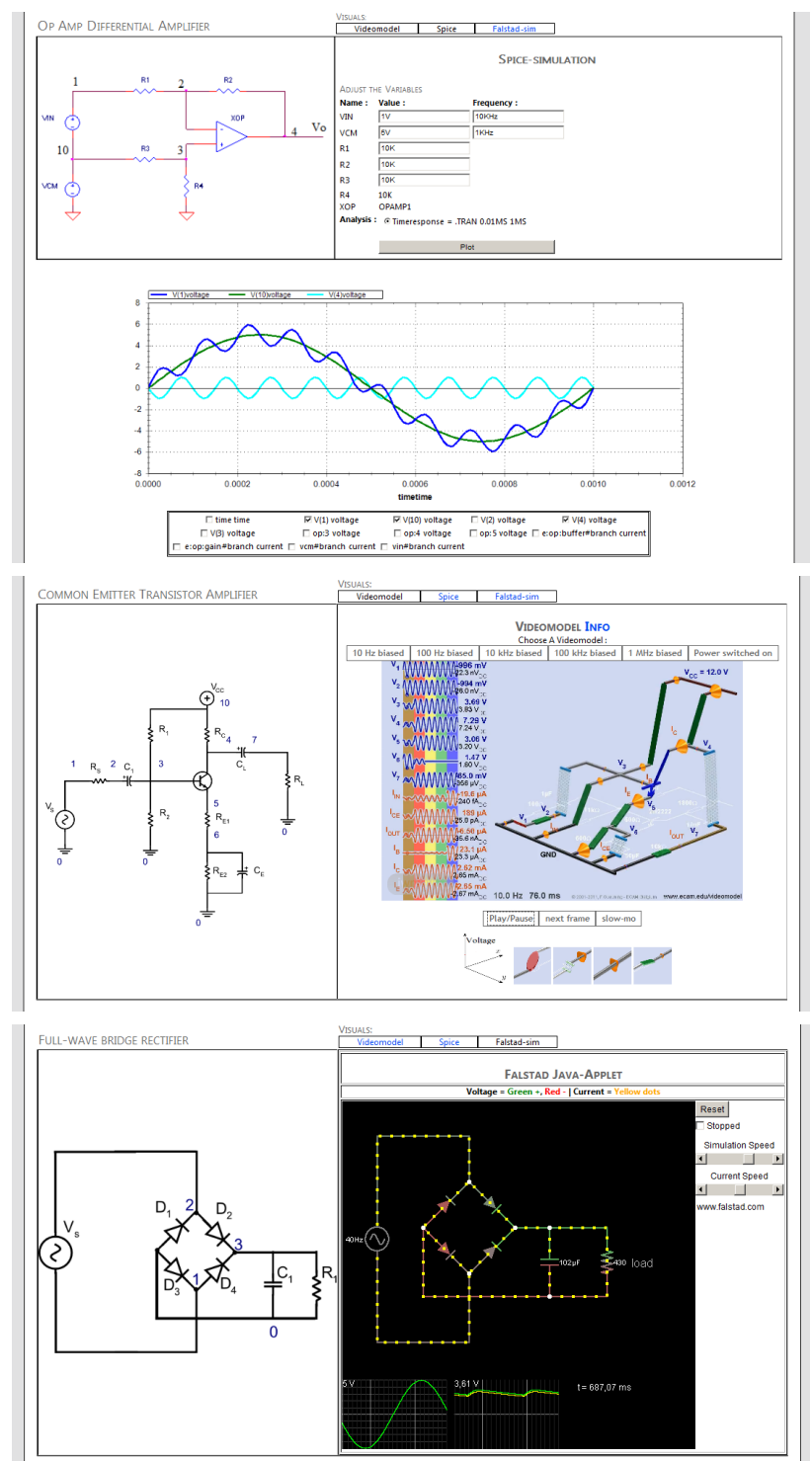

Figure 1. SPICE (top), Videomodels (middle), Falstad (bottom) in learning platform 
PAPER

COMPARATIVE STUDY OF ELECTRONICS VISUALISATION TECHNIQUES FOR E-LEARNING

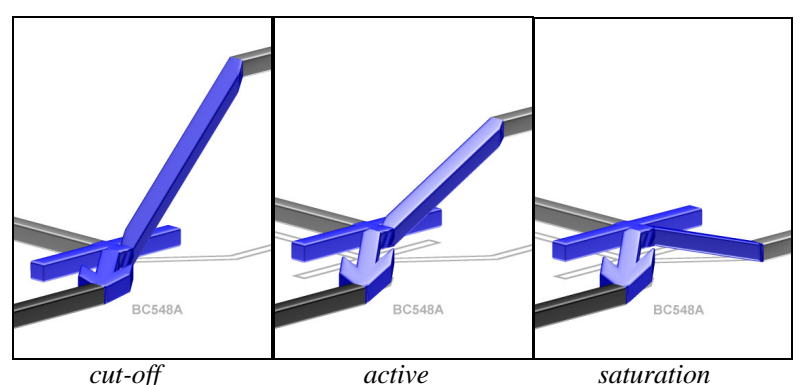

Figure 2. NPN transistor modes in Videomodels

emitter. Once students get familiar with this 3D visualization concept they can perceive the functioning of the component much faster. The current in the circuit branches is represented by a yellow-orange cone surrounding the conductor and varying in magnitude and direction, depending on the instantaneous current.

The electronic components in Videomodels are rendered for each voltage value. This is necessary due to the fact that the terminals of the component have changing voltages during operation. Figure 2 shows how an NPN transistor is rendered for different voltage values on the emitter. Once students get familiar with this $3 \mathrm{D}$ visualization concept they can perceive the functioning of the component much faster. The current in the circuit branches is represented by a yellow-orange cone surrounding the conductor and varying in magnitude and direction, depending on the instantaneous current.

Videomodels were first developed as animations, used by the teacher during the course. Later, the Videomodels were optimized to show the overall operation and detailed operation at the same time. This apparent complexity may affect off-putting to the uninitiated student. In contrast with SPICE simulators, the Videomodels only offer basic interaction with the student. These basic interactions include the choice between some existing animations and commands of the video viewer as play, pause, faster, slower, next image, and loop.

Since Video-models did not have a full-featured user interface and it was not available as an e-learning environment, we had to create in our test-setup a first order (not enhanced) web based user-interface. This was also considered an interesting opportunity to study the feasibility of user-interfaces for this kind of novel circuitrepresentation approaches. For our user-interface implementation we first searched for existing methods to present a high resolution animation on the internet. Here, several criteria were taken into account. In the first place, the quality of the images should remain high. Secondly, the size of the images should not disturb the speed of the transport in the network. Thirdly, the student should be able to easily control the images, meaning to slow down or speed up the video. Finally, the Videomodels should be independent of the used web browser and operating system. In order to meet these requirements, we have chosen for the H.264/MPEG-4 codec to compress the data of the Videomodels with a ratio of 1:7. This allows to obtain files of size between $500 \mathrm{kB}$ and $3 \mathrm{MB}$, which are manageable for transmission over the internet by means of cable connection or ADSL. We then use the Adobe Flash player as plug-in in the browser in order to run the video. Following a market research [12], 99\% of the desktop computers support this player. Finally, the open source
JW-player is used as interface between the video and the user. The player also offers an API in Javascript for programming controls for the user.

\section{Falstad simulator}

As third visualization method, we have chosen the Falstad circuit simulator [13], developed by Paul Falstad. The simulator works in the web browser as JAVA applet. The webpage of the simulator received up to today already more than a half million of visitors. Also a very successful application for the iPhone has been developed based on the simulator. Moreover, the applets of Falstad have been selected by the top multimedia for educative purposes out of 220 tools by academic institutes [14]. Moreover, the software is free and open source.

The user has in this simulator complete control over the design and visualization of the circuits. The circuits can be consulted in real time after the design. Fig. 1 (bottom) shows an example of the Falstad Circuit simulator.

\section{Overview of the characteristics}

In Table I, we summarize the most important differences between the three visualizations: simulation code, visualization of voltage, visualization of current, type of analysis, and simulation or animation with degree of interactivity.

TABLE I.

OVERVIEW OF MAIN CHARACTERISTICS IN THE 3 DESCRIBED SYSTEMS

\begin{tabular}{|l|c|c|c|}
\hline Simulation code & SPICE & Videomodel & Falstad \\
\hline $\begin{array}{l}\text { Visualization of } \\
\text { voltage }\end{array}$ & $\begin{array}{c}\text { 2D plot of } \\
\text { SPICE data }\end{array}$ & $\begin{array}{c}\text { Height in 3D } \\
\text { representation } \\
\text { of the circuit }\end{array}$ & $\begin{array}{c}\text { Java code } \\
\text { of P. } \\
\text { Falstad }\end{array}$ \\
\hline $\begin{array}{l}\text { Visualization of } \\
\text { current }\end{array}$ & $\begin{array}{c}\text { 2D plot of } \\
\text { SPICE data } \\
\text { the conductor } \\
\text { depending on } \\
\text { the instant } \\
\text { current }\end{array}$ & $\begin{array}{c}\text { Moving } \\
\text { particles } \\
\text { through a } \\
\text { conductor }\end{array}$ \\
\hline Type of analysis & All types & All types & $\begin{array}{c}\text { Only } \\
\text { transient } \\
\text { analysis }\end{array}$ \\
\hline Simulation/Animation & $\begin{array}{c}\text { Simulation, } \\
\text { Medium } \\
\text { interactivity }\end{array}$ & $\begin{array}{c}\text { Animation, at } \\
\text { this time low } \\
\text { interactivity }\end{array}$ & $\begin{array}{c}\text { Simulation, } \\
\text { High } \\
\text { interactivity }\end{array}$ \\
\hline
\end{tabular}

\section{LEARNING PLATFORM}

The e-learning platform, developed in ASP.NET, offers the three types of systems, as discussed in the previous section, to the students through a website. This website can be found on http://iwt2.ehb.be/ElektroSims. The website is modular and expandable, due to the use of XML and XLST. To perform our evaluation, we have included four basic circuits that deal about the following principles:

- An amplification in the common-emitter configuration with biasing.

- Kirchhoff's Voltage Law

- A full wave rectifier

- The active mode operation of an NPN transistor

These circuits are arbitrarily chosen from subjects out of the electronics courses during the first two years of the industrial engineering curriculum at the Erasmusho- 
geschool Brussel. For each of these subjects, one typical circuit is represented three times, in each type of multimedia. The simulations and animations are accompanied with text and images that further explain the electronic circuit concepts. Also questions are added to each circuit that can be solved within the e-learning platform in order to evaluate their understanding of the circuit.

\section{EVALUATION}

In our setting, the students have discovered and manipulated each e-learning system during approximately 15 minutes before the survey. As a consequence, we want to stress that the focus of the evaluation in our study is not on the efficiency of one of the systems. Instead, we concentrated on the usefulness and the satisfaction of the student for each of the three e-learning systems. This is called an informal study and is mainly used to summarize the positive and negative aspects of the systems [15].

The students were asked to evaluate the three multimedia systems with respect to the following criteria:

- Representation: Is the representation in the web browser clear?

- Documentation: Is there sufficient background in order to understand the multimedia?

- Concept: Is the concept (electrical or electronic component) intuitive to understand?

- Interface: Is the interface convenient and responsive?

- Result: Does the student experience that (s)he has acquired the material.

To rate the previous criteria, the students were asked to give a score following the Likert scale [16]. This score goes from 1 to 5 , corresponding to completely disagree to neutral to completely agree. The result of the evaluation for each of these five criteria is discussed in the following subsections. The corresponding histograms, for each of the criteria described above, are disposed in Fig. 2.

At the end of the survey, the students were also asked to evaluate the learning platform, consisting of three learning methods in parallel. Their opinion on the following statements was investigated

- The navigation through the content is easy.

- The courses are well organized.

- The used multimedia creates added value in electronics.

- The corresponding questions to the content help to reflect on the content.

- The platform would be a valuable addition to the existing course.

A short discussion on the e-learning platform is summarized in Subsection F.

\section{A. Representation}

A small majority of the students is not convinced about the representation of the videomodels. On the other hand, SPICE and the Falstad simulator even more, are quite successful.

On a Videomodel, there are voltage curves, numerical values, a $3 \mathrm{D}$ schematic with current cones, and all those information elements change within each image. Legibility becomes very important. In particular, it is necessary that components are shown sufficiently large. Once the

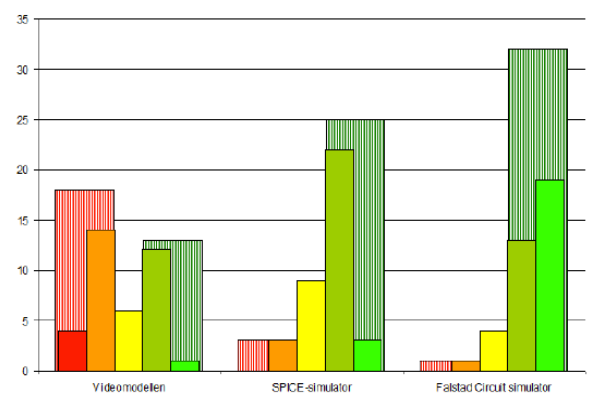

1. Representation

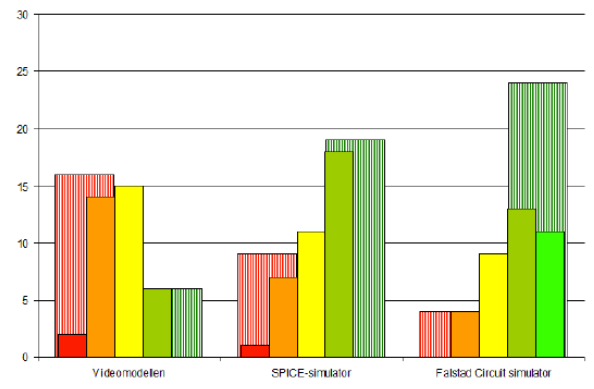

2. Documentation
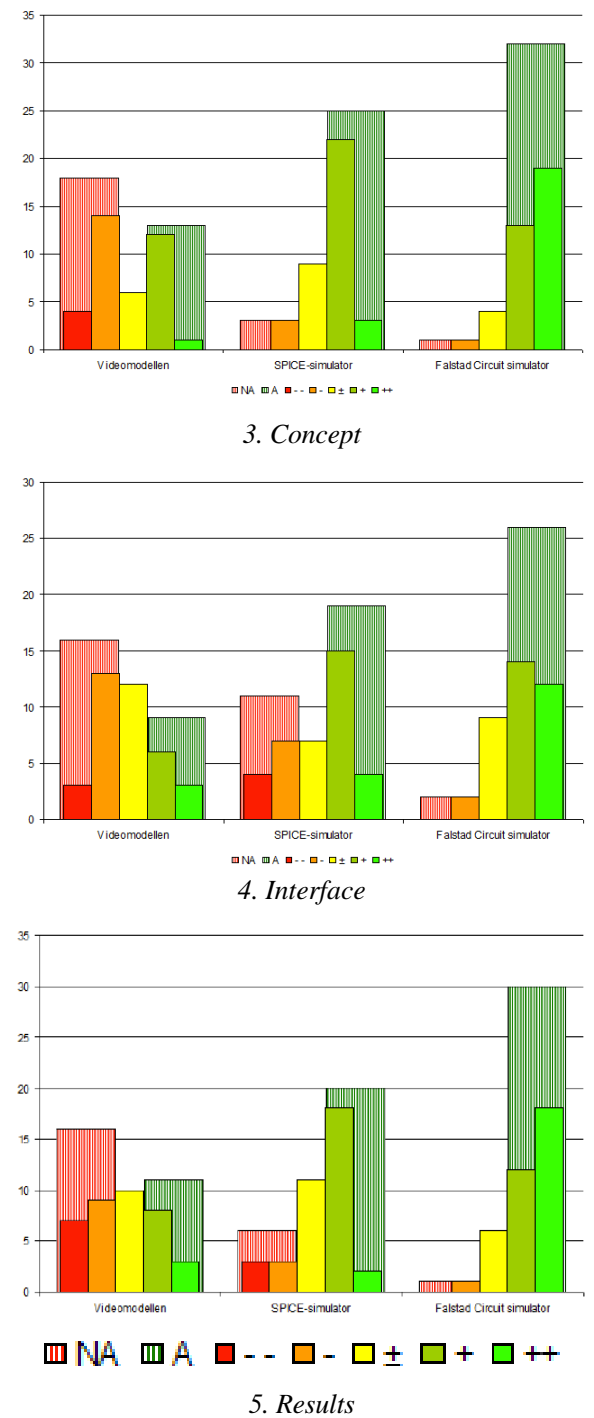

Figure 3. Comparison of Videomodels (left), SPICE (middle), Falstad (right) following the 5 criteria (In the Likert scale NA = Not Agree, A = Agree) 
brain starts knowing the components, it has less difficulty to recognize them also on smaller image as well.

In the e-learning interface developed for the Videomodels, it turned out to be difficult to reserve space for the complete Videomodel. During oral courses the whole Videomodel with all its information elements are projected which gives an added value and benefits in comparison to the e-learning approach. That's why it is necessary that during the discovery-fase of the Videomodels methodology in an e-learning environment, the first schematics are kept simple with only a few components. This way components appear bigger and interactions between the components are less complex.

\section{B. Documentation}

From the survey, we could derive that the students, especially for the Videomodels, did not find enough information on the website. Also for the SPICE simulator, there is a non negligible group that is not satisfied. Especially the Videomodels require, due to their unique representation and conventions, a more extensive introduction than the other systems. This introduction could be consulted in a pdf file after activating a link on the web page. However, after traffic analysis of the network, it turned out that very few students really took the time to consult this information into detail. This stresses the need to develop a more user-friendly and easy accessible help system. In the next version of the e-learning platform, the help pages will be much shorter, more concrete, and easily accessible besides the circuit-animation video (for instance by means of balloons).

When implementing the SPICE simulator, the functionalities and the symbols were thought to be very straightforward, which was clearly not the case for the students. Finally, for the Falstad simulator, there was one remark from a student from which we could derive that he dit not see immediately that it is possible to build the complete circuit himself.

\section{Concept}

It is remarkable to note for the Falstad simulator the unanymously positive response on the intuitive understanding of the concept. Instead, for the SPICE simulator there is a minority that is not convinced, while for the Videomodels this unsatisfied group is even larger.

It is clear that the outcome of the evaluation on this criteria is highly correlated by the outcome of the previous points. If students do not take the time to go seriously through the manual, they will also not understand the basic ideas of the system.

\section{Interface}

Here, the quality of the controls and the interaction of the tools is questionized. For the Videomodels, there is a large group of students that finds the buttons for slowing down and speeding up the video very unhandy. In the SPICE simulator, especially the communication with the SPICE service is criticized. Again the Falstad simulater obtains the most positive reactions on ease of use.

\section{E. Results}

This question asks the opinion of the student about the efficiency of the learning system. As aspected from the previous evaluation criteria, it is the Falstad generator that wins the game, followed by the SPICE generator, and ended by the first version of our Videomodels web interface.

\section{F. Learning platform}

The properties of the elcctronic learning platform were generally well accepted by the students. Only 6 negative scores out of the 185 answers clearly support the success of the platform. Especially the corresponding questions to the content are highly appreciated. The majority of the students also support the complete realization of the platform, meaning the combination of the three systems.

\section{ANALYSIS}

As mentioned before, there is a high correlation between the evaluations of the different criteria. Let us now discuss each model separately and summarize the most important lessons learned.

\section{A. Videomodels}

The Videomodels are heavily used as tool at ECAM to explain the concepts during the courses electronics. They are very successful and highly appreciated by many students. However, the Videomodels received in our study the most negative marks for all the criteria.

Nevertheless, when interpreting these results, one should take into account that the students, doing the survey, did not have any background on the material. Moreover, they had limited time (i.e. 60 minutes) to go through the four examples into three different methodologies and to complete the survey. Consequently, a large part of the students did not take the time to go thoroughly through the manual.

We were surprised about this result, since we believe that Videomodels are a very powerful method to get quickly an idea of all the relevant parameters in an electronic circuit. The quality of the information is much higher compared to any other two dimensional representation. Moreover they look very fancy and attractive. Consequently, we can conclude that it seems that the majority of the students do not take the effort to first study the manual in order to be able to use all the functionalities of the system, when "easier" alternatives are available. Also, we have to take into account the fact that the $3 \mathrm{D}$ perception and component identification is not straightforward for many students. It is probably necessary to make the discovery of videomodels more gradual to avoid that someone who starts at the top must resort to an auxiliary aid like a manual.

After the study, we also formulated several other remarks that would help to improve the interface and perception.

- Some videos, accompanied by voice, could be interesting to guide students through some examples.

- The manual should not be hiden behind a link, but preferably already visible at the front page.

- A first contact e.g. during courses, is advisable. The brain need some time to adapt to a three dimensional representation. Moreover, for some students guidance through a Videomodel is required during the first contact. It seems that some students get lost when trying to read a Videomodel, since they do not know at which side to look first. 
- Interactivity is a highly appreciated feature in elearning. Currently, the responsiveness of the buttons for selecting an image in the video can be improved. One way to deal with this is to work on the images in Javascript, rather than using a viewer like JWplayer. The main problem with Javascript is that the number of image files is much larger than the number of video files. However, the advantage is that the buttons become much more repsonsive, which make it possible to go directly to the desired image. Javascript is also very suitable to make the interface more attractive.

\section{B. SPICE simulator}

The first application of the SPICE webservice, being the SPICE graphs, received positive marks of the student. The most negative properties of the simulator were the lack of documentation and the look of the interface. Also the speed of the simulation could be improved by means of other protocols or by compression of the data during the exchange. Since the SPICE simulator is designed as a webservice, any other software developper can use the code and only has to focus on the implementation of improved graphic user interfaces by e.g. making the animations more graphically and the service more interactive.

\section{Falstad simulator}

The Falstad simulator received the best marks for all five criteria, with only eight negative comments out of the 185 scores. We could clearly distinguish a lot of enthusiasm for the simulator. The very high appreciation of the Falstad simulator above the other learning methods, shows that interaction and simplicity in representation are very crucial aspects for multimedia in electronics.

One should also take into account that the Falstad simulator was already developed as internet application for many years. For the other two systems, SPICE and Videomodels, we developed the e-learning applications ourselves, which implies that the interface and documentation can not immediately compete with a wellestablished system as the Falstad simulator.

\section{CONCLUSION AND FUTURE WORK}

In this paper we have described the development and evaluation of an interactive learning platform that consists of three different e-learning systems to illustrate the principles in electronic circuits. The main conclusion that can be drawn is that in the area of multimedia in elearning, interactivity and simplicity are the key components of a successful system.

Students appreciated the presence of the three systems in parallel, since all of them have unique added value. The comments and remarks given by the students in the survey should be taken into account in future work, leading in the first place to an improvement of the interface and documentation in the e-learning systems SPICE and Videomodels. Secondly, all the topics treated in the regular courses electronics should be included in the learning platform. Most of the students appreciated the presence of the three systems in parallel.

\section{ACKNOWLEDGMENT}

This paper is a result of the project "Bilingual learning environment for 3D visualizations of current and voltage in electric and electronic circuits", sponsored by the Prins Filip Fonds in Belgium. It was a collaboration between the Erasmushogeschool Brussel and the Haute Ecole Léonard de Vinci.

\section{REFERENCES}

[1] J. Hospodka en J. Bicak, "Web-Based application for electric circuit analysis,” in 2009 Fourth International Multi-Conference on Computing in the Global Information Technology, Cannes/La Bocca, France, 2009, pp. 157-160.

[2] S. C. Wang en Y. H. Liu, "Software-reconfigurable e-learning platform for power electronics courses," Industrial Electronics, IEEE Transactions on, vol. 55, nr. 6, p. 2416-2424, 2008.

[3] V. Fedak en P. Bauer, "E-learning in education of electrical drives and power electronics: opportunities and challenges,” in Proceedings of the 15-th International Conference on Electrical Drives and Power Electronics, 2005, p. 1-9.

[4] U. Drofenik en J. Kolar, "Interactive power electronics seminar (ipes)-a web-based introductory power electronics course employing java-applets," in Power Electronics Specialists Conference, 2002l, vol. 2. IEEE, 2002, pp. 443-448.

[5] Y. Chavan, "Assessing effectiveness of interactive electronics lab simulation: Learners Perspective.”, Turkish Online Journal of Distance Education, Vol 10, No. 1.

[6] J. Hamar, H. Funato, S. Ogasawara, O. Dranga, en C. K. Tse, "Multimedia based e-learning tools for dynamic modeling," in of DC-DC Converters, IEEE International Conference on Industrial Technology (IEEE-ICIT 2005), Hong-Kong, December 14-17, 2005.

[7] L. W. Nagel en D. Pederson, "Spice (simulation program with integrated circuit emphasis)," EECS Department, University of California, Berkeley, Tech. Rep. UCB/ERL M382, Apr 1973.

[8] B. Wilamowski, A. Malinowski, en J. Regnier, "Internet as a new graphical user interface for the SPICE circuit simulator,” Industrial Electronics, IEEE Transactions on, vol. 48, nr. 6, pp. 12661268, 2001.

[9] B. Swiercz, L. Starzak, M. Zubert, en A. Napieralski, “An interactive website as a tool for CAD of power circuits," in Tech. Proc. 2003 Nanotech. Conf. Trade Show (NanoTech), 2003, pp. 346349.

[10] L. Sterckx, Vergelijkende studie van elektronische visualisatietechnieken voor e-learning, Master thesis, Erasmushogeschool Brussel, 2011.

[11] F. Gueuning, "Vidéomodèles, méthode de visualisation 3D des circuits électriques en fonctionnement," J3eA, vol. 4, nr. HORS SERIE 2, p. 8, 2005.

[12] M. Brown. Flash content reaches $99 \%$ of internet viewers. [Online available]:http://www.adobe.com/products/playercensus/flashplay er/

[13] P. Falstad, "Math and physics applets,” URL: http://www. falstad. com/mathphysics. html, 2006.

[14] M. Benedict, E. Debowska, H. Jodl, L. Mathelitsch, en R. Sporken, "Report and recommendations on available multimedia material for teaching optics at school and at university level," in $8^{\text {th }}$ Workshop on Multimedia in Physics Teaching and Learning of the European Physical Society - Proceedings, (Prague, Czech Republic 2003).

[15] R. C. Clark en R. E. Mayer, E-learning and the science of instruction: proven guidelines for consumers and designers of multimedia learning. John Wiley and Sons, september 2007.

[16] R. Likert, “A technique for the measurement of attitudes.” Archives of psychology, 1932. 
PAPER

COMPARATIVE STUDY OF ELECTRONICS VISUALISATION TECHNIQUES FOR E-LEARNING

\section{AUTHORS}

A. Touhafi is a professor at Erasmushogeschool Brussel and Vrije Universiteit Brussel where he teaches various courses on analog and digital electronics(e-mail: abdellah.touhafi@vub.ac.be). He is also the chairman of the educational board of the industrial engineering sciences department and is heading the Electronics-lab research group.

A. Braeken, is a professor at the Erasmushogeschool Brussels where she teaches various courses on informatics and mathematics (e-mail: an.braeken@ehb.be).
F. Gueuning, is a professor at Haute Ecole Léonard de Vinci where he teaches various courses on electronics (email: f.gueuning@ecam.be).

L. Sterckx, was a master student at Erasmushogeschool Brussel.

Y. Verbelen is an education assistant and researcher at Erasmushogeschool Brussel and Vrije Universiteit Brussel. (e-mail: yannick.verbelen@ehb.be).

This article is an extended version of a paper presented at the International Conference IEEE EDUCON2012, held in April 2012, in Marrakesh, Morocco. Received, 22 April 2012. Published as resubmitted by the authors 30 April 2012 